American Journal of Applied Sciences 7 (5): 634-639, 2010

ISSN 1546-9239

(C) 2010Science Publications

\title{
Prevalence of Low Back Pain and its Risk Factors among School Teachers
}

\author{
${ }^{1}$ Nurul Izzah Abdul Samad, ${ }^{2}$ Haslinda Abdullah, ${ }^{3}$ Saidi Moin, \\ ${ }^{1}$ Shamsul Bahri Mohd Tamrin and ${ }^{1}$ Zailina Hashim \\ ${ }^{1}$ Department of Community Health, Faculty of Medicine and Health Science, \\ ${ }^{2}$ Department of Social and Developmental Science, Faculty of Human Ecology, \\ ${ }^{3}$ Department of Biomedical Science, Faculty of Medicine and Health Science \\ University Putra Malaysia, 43400 Serdang, Selangor, Malaysia
}

\begin{abstract}
Problem statement: The objective of this study was to determine the prevalence of low back pain and the associated risk factors among primary school teachers in the Klang Valley, Malaysia. Approach: A cross sectional study was conducted in nine primary schools in the Klang Valley. The schools were selected randomly from a list obtained from the Ministry of Education. Two hundred and seventy two respondents who fulfilled the study criteria volunteered to participate in the study. A questionnaire was used to determine the demographic and occupational information. Information on low back pain was assessed using a Nordic Questionnaire, while the General Health Questionnaire was used to determine the mental health status. Results: The prevalence of low back pain was $40.4 \%$ among respondents. Lifting load $(28.0 \%)$ was ranked as the main factor which contributed to low back pain, followed by prolonged sitting (25.2\%). Poor mental health (OR 1.11, 95\% CI 1.06-1.15) was the risk factor to low back pain. Conclusion: The prevalence of low back pain was $40.4 \%$ among primary school teachers in Klang Valley. Teachers with poor mental health status had higher risk of developing low back pain.
\end{abstract}

Key words: Primary school teachers, low back pain, mental health status

\section{INTRODUCTION}

The issue of musculoskeletal problems in adult population is overwhelming. A study in Canada and North America proved that low back pain was the leading cause of disability and morbidity in middle-aged person which was by far the most expensive source of workers' compensation costs (Manga et al., 1993). Low back pain is very common that almost half of the adult population suffered from low back pain which last for more than $24 \mathrm{~h}$ at times during the year (Tessa, 2010) and often causes lost workdays (Guo et al., 1999). About $11.6 \%$ out of 2600 populations in a semirural area, Malaysia were diagnosed with low back pain problem (Veerapen et al., 2007). Low back pain does not only signify poor quality of individuals' life, but also showed decreased in labor productivity due to offwork, absenteeism and early retirement (Tsuboi et al., 2002).

Low back pain cases associated with an initial episode could be resolved within 2-4 weeks (McKeon et al., 2006). It had been observed that individuals who suffered from low back pain problems might develop major physical, social and mental disruptions, which could affect their occupations (Tavafian et al., 2007). Physical impact include the loss of physical function and deteriorated general health. Social impact included decreased participation in social activities. Psychosocial impacts are manifested through insomnia, irritability, anxiety and depression (Clairborne et al., 2002). Previous studies reported that there were significant relationship between psychosocial variables and musculoskeletal disorders (Tsuboi et al., 2002; Ariens et al., 2001; Chiu et al., 2006).

According to Lemoyne et al. (2007) some European studies suggested that physical education teachers involved in high energy consumption with a high potential of acute and chronic injuries, often lead to premature retirement. Sandmark (2000) stated that physical education teachers were more often absent from work and also more likely to anticipate early retirement. A study in Ireland showed that one of the leading causes for ill health retirement among school teachers was musculoskeletal problems, which

Corresponding Author: Zailina Hashim, Department of Community Health, Faculty of Medicine and Health Science, University Putra Malaysia, 43400 Serdang, Selangor, Malaysia 
Am. J. Applied Sci., 7 (5): 634-639, 2010

contributed to $10 \%$ of the ill health retirement in the population (Maguire and O'Connell, 2007). Broad investigations have been made for the school environment with regards to children safety, with some of them suggesting an ergonomics improvement on the school furniture (Linton et al., 1994); however very little attention had been given to furniture for teachers. Therefore, there is a need to study the problem of musculoskeletal pain among school teachers. The purpose of this study was to determine the prevalence of low back pain and to investigate the associated risk factors among primary school teachers in the Klang Valley, Malaysia.

\section{MATERIALS AND METHODS}

Location and background of respondents: The schools selected were Grade A national primary schools located in the Klang Valley. Grade A school is defined as schools that have more than 500 students in urban and industrial areas while for the rural area, these are schools with more than 200 students. Written consent was obtained from the Ministry of Education, the State and the Districts where the schools are located. Random sampling was carried out from the list of Grade A schools located in the districts of Petaling Jaya, Kuala Lumpur, Klang, Hulu Langat and Kuala Langat. Four of the school are located in the urban areas, 2 schools are from the industrial areas and 3 schools are from the rural area. Teacher's name lists were obtained from the school administrator. Teachers who met the criteria such as full time teachers, had a minimum of one-year teaching experience, not under any medication and did not consume alcohol were invited as respondent. Two hundred and seventy two teachers volunteered to participate. Each teacher was given a consent letter and a document describing the procedure of the study and its objectives. The questionnaire was self-administered and took about 20 min to fill out.

Questionnaire: The questionnaire consists of three parts. The first part of the questionnaire was on the respondent's demographic factors which included age, gender, marital status, years of formal education and teaching experience. The second part of the questionnaire investigated the musculoskeletal problems. A modified Nordic questionnaire (Kuorinka et al., 1987) was used to assess the body parts with musculoskeletal disorders and their perceptions on health risks at work. It was translated from English to the Malay language, for better understanding of the respondents. The third part of the questionnaire focused on the respondents' psychosocial factors using the General Health Questionnaire (Goldberg and Hilier, 1979) which measured the common mental health problems/domains of depression, anxiety, somatic symptoms and social withdrawal. The questions included were 'have you lost much sleep'? 'have you felt capable of making decisions about things'? and 'have you felt constantly under strain'? The score was based on Likert Scale with 0 for "not at all", 1 for "sometimes", 2 for "more than sometimes" and 3 for "often". The questionnaire was self-administered with supervision of the researcher; a short briefing was carried out before the data collection. The questionnaire showed a good reliability test with Cronbach alpha of 0.901 . Univariate analysis used in determining the descriptive statistics, which were prevalence and activities contributed to the low back pain. A binary logistic regression adjusted for body mass index, history of accident and physical activities was used to determine the associated risk factors.

\section{RESULTS}

Background information: Questionnaires were distributed and filled out by 272 respondents who volunteered to participate in the study. A total of $67 \%$ of the respondents were female, $81.3 \%$ were married and $57.4 \%$ were classroom teachers (Table 1 ). The average employment years was 10 years with at least 7 h spent on teaching. Most of the respondents (56.3\%) have certificate of education, with an average monthly salary of RM2495.59 (USD773.70).

\begin{tabular}{lr} 
Table 1: Respondents background & $\mathrm{n}(\%)$ \\
\hline Variables & \\
\hline Gender & $191(33.5)$ \\
Male & \\
Female & $221(81.3)$ \\
Marital status & $42(15.4)$ \\
Married & $9(3.3)$ \\
Single & \\
Divorced & $153(56.3)$ \\
Education level & $26(9.6)$ \\
Certificate & $93(34.2)$ \\
Diploma & \\
Bachelor & $102(37.5)$ \\
Job responsibility & $156(57.4)$ \\
Subject teacher & $14(5.1)$ \\
Classroom & \\
teacher & $239(87.9)$ \\
Administrator & $33(12.1)$ \\
Mental health status & \\
Good & \\
Poor & Mean (SD) \\
Variable & $34.74(7.7)$ \\
Age (year) & $2495.59(594.62)$ \\
Total salary (RM) & $10(4.73)$ \\
Work experience (year) & $7(1.45)$ \\
Work duration (h) & \\
\hline $\mathrm{n}=272$ &
\end{tabular}


Am. J. Applied Sci., 7 (5): 634-639, 2010

Table 2: One year prevalence of low back pain among respondents

\begin{tabular}{lcr}
\hline Variable & Yes n (\%) & No n (\%) \\
\hline $\begin{array}{l}\text { Low back pain } \\
\text { Gender }\end{array}$ & $110(40.4)$ & $162(59.6)$ \\
Male & $36(39.6)$ & \\
Female & $87(48.1)$ & $55(60.4)$ \\
School location & & $94(51.9)$ \\
Urban & $56(46.3)$ & \\
Industry & $35(40.2)$ & $65(53.7)$ \\
Rural & $32(47.8)$ & $49(59.8)$ \\
Job responsibility & & $35(52.2)$ \\
Subject teacher & $44(43.14)$ & \\
Classroom teacher & $70(44.87)$ & $58(56.86)$ \\
Administrator & $9(64.23)$ & $86(55.13)$ \\
\hline $\mathrm{n}=272$ & & $5(35.77)$ \\
\hline
\end{tabular}

Table 3: Respondents' perception on activities that contributed to low back pain

\begin{tabular}{lll}
\hline Activity & $\mathrm{n}(\%)$ & Ranking \\
\hline Lifting load & $31(28.0)$ & 1 \\
Prolonged sitting & $30(27.0)$ & 2 \\
Prolonged standing & $26(23.4)$ & 3 \\
Others (physical education & $15(13.5)$ & 4 \\
activities, walking up and down & & \\
the stairs and writing on board) & & \\
Working with computer & $7(6.3)$ & 5 \\
Not sure & $2(1.8)$ & 6 \\
\hline
\end{tabular}

$\mathrm{n}=111$

Prevalence of low back pain: The prevalence of low back pain was $39.6 \%$ among men and $48.1 \%$ among women, respectively. Prevalence of low back pain problems were reported to be $47.8 \%$, in the rural areas $46.3 \%$ in the urban and $40.2 \%$ in the industrial areas (Table 2). Table 3 shows that the main task reported to contribute to low back pain in schools were lifting loads. The loads were namely work books, exam papers and some heavy sport equipment carried by the physical education teachers. Prolonged sitting was the second contributing factor to the low back pain (25.2\%), followed by prolonged standing (23.4\%). Marking exam, assignments and work books resulted in prolonged sitting. Activities during physical education sessions and walking up and down the stairs were the fourth contributing factor to low back pain (13.5\%). Finally, working with computer was the fifth contributing factor (6.3\%).

Low back pain and risk factors: Table 4 shows the results of risk factor analysis on the cause of low back pain among respondents. Poor mental health status significantly increased the risk by 1.11 times compared to the normal status (OR 1.11, 95\% CI 1.06-1.15). However, no other risk factors showed significant association with low back pain. Increased risk trend were showed in urban teachers (OR 1.49, 95\% CI 0.82-2.69), rural teachers (OR 1.32, 95\% CI 0.67-2.62) and smokers (OR 1.32, 95\% CI 0.62-2.80).
Table 4: Relationship between low back pains with selected factors

\begin{tabular}{llll}
\hline Factors & Odd ratio & 95\% C.I & $\mathrm{p}$ \\
\hline School location & & & \\
Industry & $1^{\mathrm{a}}$ & & 0.41 \\
Urban & 1.49 & $0.82-2.69$ & 0.19 \\
Rural & 1.32 & $0.67-2.62$ & 0.43 \\
Teaching experience (year) & 0.99 & $0.96-1.03$ & 0.84 \\
$\begin{array}{l}\text { Daily work duration (h) } \\
\text { Job responsibility }\end{array}$ & 0.96 & $0.79-1.16$ & 0.66 \\
Administrator & & & \\
Subject teacher & $1^{\mathrm{a}}$ & & 0.49 \\
Classroom teacher & 0.52 & $0.16-1.77$ & 0.29 \\
Cigarette smoker & 0.65 & $0.19-2.14$ & 0.48 \\
No & & & \\
Yes & $1^{\text {a }}$ & & \\
Poor mental health status & 1.32 & $0.62-2.80$ & 0.47 \\
\hline $\mathrm{n}=272 ; * * *:$ Significant at & 1.11 & $1.06-1.15$ & $0.001^{* * *}$ \\
\hline
\end{tabular}

\section{DISCUSSION}

This study was an attempt to investigate the prevalence of low back pain and its associated risk factors among primary school teachers. Malaysian Ministry of Education stated that female teachers constitute the majority of school teachers in Malaysia (69.1\%) and their participation in this study (66.5\%) aligned with the provided statistic. The average age was 34 years with half of the respondents (57.4\%) were classroom teachers, $12 \%$ of the respondents showed poor mental health status which were related to stress and anxiety problems.

The results showed a higher prevalence of low back pain problem among rural (46.3\%) and urban school teachers $(47.8 \%)$ in contrast to the industrial school, even though it was not significantly associated with locations. School administrators with higher prevalence of low back pain were the older teachers, as compared to classroom and subject teachers. Older teachers generally have reduced physical capabilities and slower psychological response, compared to the young co-workers.

About $40.4 \%$ of the total respondents reported having low back pain during their teaching years. This study showed similar prevalence with the Chinese school teachers (Jin et al., 2004). In this study, female teachers showed a significantly higher prevalence of low back pain (48.1\%) than men (39.6\%). The result was consistent with a study in Hong Kong among secondary school teachers (Chiu and Lam, 2007) which showed female teachers were prone $(38.5 \%, 74.9 \%$ respectively) to develop upper limb and neck pain. A study on low back pain among school personnel in Japan also showed the same result (23.2\%) of a higher prevalence among women (Tsuboi et al., 2002). Previous studies suggested that gender differences occurred because women were more likely to report any pain 
problem than men as women tended to have a lower pain threshold than men (Chiu and Lam, 2007; Jin et al., 2004).

The job natures of school teachers included frequent reading, marking of assignments as well as writing on blackboard. Poor posture and improper techniques of lifting or carrying are the two very common causes of low back pain. Meanwhile, lifting heavy loads which ranked as the main contributing factor involved materials such as books, overhead projectors and other equipment (Tessa, 2010). They should make use of trolleys, especially when handling instruments in the laboratory. Poor posture, either seating or standing was ranked as second and third major risk factor. This included twisting such as turning from the board to the class and back again. Prolonged sitting also occurred when teachers marked and prepared work on computers. All teachers shared the same standing position favorable to the development of lower back pain (Lemoyne et al., 2007). Subject teachers which included physical education teachers perceived that movements when picking up and carrying heavy objects were the fourth cause of the low back pain (Lemoyne et al., 2007). Working with computer made one more prone to other musculoskeletal problems, such as neck pain and upper limb pain. Besides, the teachers have to crane their necks while typing; making the shoulders and backs more tense thus resulting in pain.

This study showed that mental health status which reflected psychosocial factor was the significant contributing factor to the low back pain problem among the primary school teachers. The risk factors for low back pain have been identified to include individual factors such as body weight and age, biomechanical factors such as heavy physical load, prolonged static postures and lifting and psychosocial factors such as job satisfaction, time and study demands as well as job stress (Tsuboi et al., 2002; Tamrin et al., 2007; Scuffham et al., 2009). The job natures of teachers in school included all the risk factors mentioned above.

Psychosocial factor, which include psychological risk factor refers to individual's perception of the job characteristics which can promote positive feedback (motivation and satisfaction) and stress. The more psychological demands needed for a certain tasks, the greater is the possibility to develop musculoskeletal disorder; whatever the anatomical area is (Lanfranchi and Duveau, 2008). Other studies had proved that high mental pressure showed a significant psychosocial risk factor for musculoskeletal disorder among school teachers (Tsuboi et al., 2002; Chiu and Lam, 2007) and Japanese nurses (Smith et al., 2006). Other occupations that showed a high prevalence of low back pain also demonstrated the relationship with psychological or psychosocial factors (Tamrin et al., 2007; Scuffham et al., 2009; Harreby et al., 1996).

The odd ratio showed the strength of association between low back pain and risk factor such as school location and smoking habit, which was not significant. Urban teachers (OR 1.49, 95\% CI 0.82-2.69) and rural teachers (OR 1.32, 95\% CI 0.67-2.62) were prone to develop low back pain due to various factors, such as less number of teachers in schools from these area, compared to the urban and industrial areas. As a result there was an increased in job demand with extra responsibility and additional workload. Urban schools normally have large number of classes, but have more facilities. There would be more space in these school environments for the subjects to do physical activities in between teaching and learning. Convenient school environment can be described as having sufficient space for the teachers and students for activities and to place ergonomically designed furniture in classroom and teachers' room. Smoking showed a trend of increased risk for low back pain (OR 1.32, 95\% CI 0.62-2.80) which was consistent with other studies (Jin et al., 2004; Lei et al., 2004; Scott et al., 1999) However, Scott et al. (1999) suggested that data on smoking initiation and patterns of smoking were needed for the causality to be made.

\section{CONCLUSION}

This study showed that the prevalence of low back pain among the primary school teachers was $40.4 \%$. Lifting heavy loads were perceived by respondents as the main activity which resulted in the development of low back pain. However, statistical results showed that mental health status was the main contributor to low back pain. It was concluded that poor mental health status had a significant relationship with low back pain.

\section{ACKNOWLEDGEMENT}

The researcher would like to thank the Malaysian Ministry of Education, the management of the primary schools and teachers for their cooperation and participation in this study. The research was supported by Research University Grant Scheme (No. 91127), University Putra Malaysia. 


\section{REFERENCES}

Ariens, G.A., P.M. Bongers, W.E. Hoogerndoorn, I.L. Houtman and G. Van Der Wal et al., 2001. High quantitative job demands and low coworker support as risk factors for neck pain: Results of a prospective cohort study. Spine, 26: 1896-1901. PMID: 11568702

Chiu, T.W., K.T. Lau, C.W. Ho, M.C. Ma and T.F. Yeung et al., 2006. A study on the prevalence of and risk factors for neck pain in secondary school teachers. Public Health, 120: 563-565. PMID: 16684548

Chiu, T.T.W. and P.K.W. Lam, 2007. The prevalence of and risk factors for neck pain and upper limb pain among secondary school teachers in Hong Kong. J. Occup. Rehabilit., 17: 19-32. DOI: 10.1007/s10926-006-9046-z

Clairborne, N., H. Vandenburgh, T.M. Krause and P. Leung, 2002. Measuring quality of life changes in individuals with chronic low back pain conditions: A back education programme evaluation. Evaluat. Programme Plann., 25: 61-70. DOI: 10.1016/S0149-7189(01)00049-0.

Goldberg, D.P. and V.F. Hilier, 1979. A scaled version of the general health questionnaire. Psychol. Med., 9: 139-145. PMID: 424481

Guo, H.R., S. Tanaka, W.E. Halperin and L.L. Cameron, 1999. Back pain prevalence in US industry and estimates of lost workdays. Am. J. Public Health, 89: 1029-1035. PMCID: PMC1508850

Harreby, M., J. Kjer, G. Hesselsoe and K. Neergaard, 1996. Epidemiological aspects and risk factors for low back pain in 38-year-old men and women: A 25-year prospective cohort study of 640 school children. Eur. Spine J., 5: 312-318. PMID: 8915636

Jin, K., G.S. Sorock and T.K. Courtney, 2004. Prevalence of low back pain in three occupational groups in Shanghai, people's republic of China. J. Safety Res., 35: 23-28. PMID: 14992843

Kuorinka, I., B. Jonsson, A. Kilborn, H. Vinterberg and F. Biering-Sorensen et al., 1987. Standardised nordic questionnaires for the analysis of musculoskeletal symptoms. Applied Ergon., 18: 233-237. PMID: 15676628

Lanfranchi, J.B. and A. Duveau, 2008. Explicative Models of Musculoskeletal Disorders (MSD): From biomechanical and psychosocial factors to clinical analysis of ergonomics: Modèles explicatifs des troubles musculosquelettiques (TMS): Des facteurs biomécaniques, psychosociaux à la clinique du geste. Rev. Eur. De Psychol. Applied//Eur. Rev. Applied Psychol., 58: 201-213. DOI: 10.1016/j.erap.2008.09.004
Lemoyne, J., L. Laurencelle, M. Lirette and F. Trudeau, 2007. Occupational health problems and injuries among quebec's physical educators. Applied Ergon., $\quad 38$ : 625-634. DOI: 10.1016/j.apergo.2006.06.004

Lei, L., P.G. Dempsey, J.G. Xu, L.N. Ge and Y.X. Liang, 2004. Risk factors for the prevalence of musculoskeletal disorders among Chinese foundry workers. Industrial J. Ind. Ergon., 35: 197-204. DOI: 10.1016/j.ergon.2004.08.007

Linton, S.J., A.L. Hellsing, T. Halme and K. Akerstedt, 1994. The effects of ergonomically designed school furniture on pupils' attitudes, symptoms and behavior. App. Ergon., 25: 299-304. DOI: 10.1016/0003-6870(94)90044-2

Maguire, M. and T. O’Connell, 2007. Ill health retirement of schoolteacher in the republic of Ireland. Occup. Med., 57: 191-193. DOI: 10.1093/occmed/kqm001

Manga, P., D.E. Angus, C. Papadopoulus and W.R. Swan, 1993. A study to examine the effectiveness and cost effectiveness of chiropractic management of low back pain: The Manga Report. http://www.ncschiropractic.com/manga.htm

McKeon, M., W.J. Albert and J.P. Neary, 2006. Assessment of neuromuscular and hemodynamic activity in individuals with and without chronic low back pain. Dyn. Med., 5: 6. DOI: 10.1186/1476-5918-5-6

Sandmark, H., 2000. Musculoskeletal dysfunction in physical education teachers. Occup. Environ. Med., 57: 673-677. DOI: 10.1136/oem.57.10.673

Scott, S.C., M.S. Goldberg, N.E. Mayo, S.R. Stock and B. Poitras, 1999. The association between cigarette smoking and back pain in adults. J. Spine, 24: 1090. PMID: 10361658

Scuffham, A.M., S.J. Legg, E.C. Firth and M.A. Stevenson, 2009. Prevalence and risk factors associated with musculoskeletal discomforts in New Zealand veterinarians. Applied Ergon., 41: 444-453. DOI: 10.1016/j.apergo.20 09.09.2009

Smith, D.R., M. Mihashi, Y. Adachi, H. Koga and T. Ishitake, 2006. A detailed analysis of musculoskeletal disorders among Japanese nurses. J. Safe. Res., 37: 195-200. DOI: 10.1016/j.jsr.2006.01.004

Tamrin, S.B.M., K. Yokoyama, J. Jalaludin, N.A. Aziz and N. Jemoin et al., 2007. The association between risk factors and low back pain among commercial vehicle drivers in peninsular Malaysia: A preliminary result. Ind. Health, 45: 268-278. DOI: 10.2486/indhealth.45.268 
Tavafian, S.S., A. Jamshidi, K. Mohammad and A. Montazeri, 2007. Low back pain education and short term quality of life: A randomized trial. MBC Musculoskeletal Disorders, 8: 21. DOI: 10.1186/1471-2474-8-21

Tessa, 2010. Is teaching bad for your back? Teachingexpertise.

http://www.teachingexpertise.com/articles/teaching -bad-back-598
Tsuboi, H., K. Takeuchi, M. Watanabe, R. Hori and F. Kobayashi, 2002. Psychosocial factors related to low back pain among school personnel in Nagoya, Japan. Ind. Health, 40: 266-271. PMID: 12141375

Veerapen, K., R.D. Wigley and H. Walkenburg, 2007. Musculoskeletal pain in Malaysia: A COPCORD survey. J. Rheumatol. 34: 207-213. PMID: 17216688 